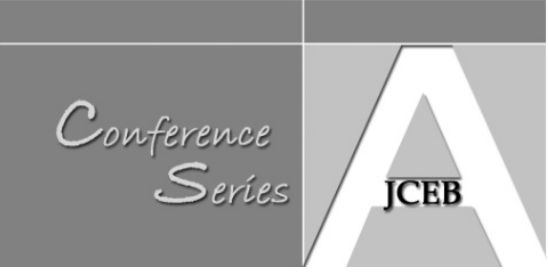

\title{
Paving the Road for Sustainable Construction in Developing Countries: A Study of the Jordanian Construction Industry
}

Suhair G Alkilani and Julie R Jupp (University of Technology Sydney, Australia)

\begin{abstract}
There is an increasing pressure on governments of developing economies to support sustainable construction procurement. In exploring this issue, this research asks three related questions: (1) how is sustainable procurement perceived in developing economies, (2) how can government regulation influence its application, and (3) what is the role of performance measurement in stimulating sustainable procurement practices? Answers are sought via an investigation exploring the underlying issues and challenges facing the construction industry of a developing country looking to address sustainable procurement. Using primary and secondary data sources, this research presents a case study of the Jordanian construction industry. Findings show that whilst sustainable procurement practices are promoted, it is still in its infancy - in part due to ineffective procurement frameworks and a lack of performance measurement. Current government regulations and policies are identified as an underlying cause, discouraging the development and adoption of sustainable procurement methods. As the Jordanian construction industry shares characteristics with other developing economies, it is expected that the findings of this paper will be of interest to professionals in those construction industries attempting to initiate sustainable procurement via performance measurement.
\end{abstract}

Keywords: Sustainable procurement, performance measures, developing countries, construction

\section{Introduction}

There is an increasing interest, across both the private and public sectors, to understand and define sustainable construction practices (Adrien and Laura 2010). In considering the social, economic and environmental issues, performance measurement and benchmarking processes are ways that the construction industry can move towards attaining sustainable procurement and development (Shah et al. 2010). Key Performance Indicators (KPIs) are commonly defined for this purpose (Ofori 2001). Developed economies are taking both reactive and proactive steps towards the sustainable construction procurement by establishing regulations and controls, introducing economic incentives, and initiating non-regulatory activities (Spence and Mulligan 1995). For example, in 2003 following the recommendations of the Latham (1994) and Egan (1998) reports the UK's National Procurement Strategy (NPS) was introduced, and the Construction Procurement Policy later produced in 2006. These initiatives confirmed the importance of 'proper' procurement in construction (Thomson and Jackson 2007). Similarly, in 2007 the Australian Procurement and Construction Council introduced Australian and New Zealand Government Framework for Sustainable Procurement was introduced (APCC 2012).

However, this is not the norm in many developing economies (Ofori 1992) where a construction industry must be considered more prudently in relation to its country's economic and social context. Such countries face poverty, resource shortages, complicated environmental challenges, and are often characterised by rapid population growth and increasing levels of urbanisation (Geng and Doberstein 2008). In such situations, government and private business initiatives for sustainable construction are often missing. In some 
instances, such as Jordan, general frameworks and indicators for the construction industry are lacking, where Key Performance Indicators (KPIs) targeting sustainable practices are absent (Alkilani et al. 2012). In exploring these issues, this research asks three research questions:

1) How is sustainable procurement perceived in developing economies?

2) How does government regulation influence its application?; and

3) What is the role of performance measurement in stimulating sustainable procurement?

In the following sections, background literature is reviewed across relevant fields of research. Coverage includes an overview of the key sustainability issues affecting construction, government initiatives addressing sustainability, and existing approaches to sustainable construction procurement. The research methodology and case study findings are then presented. The findings show that whilst sustainable practices are promoted, the construction industry lags in its response not only to sustainable procurement methods but to sustainability generally. The paper then presents recommendations aimed at supporting sustainable construction procurement and unifying the actions of construction industry actors. Recommendations are proposed in an integrated strategy that incorporates the macrodimension (government structures) and micro-dimension (industry behaviours). The paper concludes with a discussion of main research findings.

\section{Sustainable Development and Procurement in Construction}

During the past decade, sustainable development has become an important aspect of construction industries (Wilkinson 2007). Khalfan (2006) defined sustainable construction as a process carried out by integrating the main objectives of sustainable development, and defining a 'three-legged stool' of development based on satisfying: environmental, economic and social requirements. As a construction industry moves toward sustainable procurement, it becomes important that adequate management tools and methodologies are available (Adrien and Laura 2010), and indicators of sustainability are defined and employed (Ding 2008).

In the design, delivery and operation of buildings, there has been rapid development in sustainability and assessment tools (Wilkinson 2007). For example the US's LEED scheme, the UK's Building Research Establishment Environmental Assessment Method (BREEAM), and the Australian 'GreenStar' assessment tools have been introduced to assess the environmental impact of building designs and benchmark the sustainability of designs against recognised industry standards, measures and performance criteria (Ding 2008). Life Cycle Cost (LCC) analysis has also been introduced to inform design decision-making , enabling the costs of acquiring, owning, and disposing of a building or building system to be taken into account (Hassan 2006)

Underpinning the aforementioned initiatives, public procurement methods have begun to focus on sustainability via the development of the 'sustainable procurement' concept (Dickinson et al. 2008). According to the United Nations Development Programme (UNDP (2008), sustainable procurement means ensuring that the buying of products and services is as sustainable as possible, with the lowest environmental impact, greatest economic effectiveness and in a way that has positive social impact. In the context of construction, sustainable procurement is a process whereby the client and participating organisations meet design and development requirements in a way that achieves value for money on a whole life basis - so as to generate benefits not only for project stakeholders but also to society and the economy, while minimising any environmental damage. Sustainable construction

Alkilani, S.G. and Jupp, J.R. (2012) 'Paving the road for sustainable construction in developing countries: a study of the Jordanian construction industry', Australasian Journal of Construction Economics and Building, Conference Series, 12 (1) $84-93$ 
procurement therefore promotes the three-legged stool of sustainability, (UNDP 2008). Sustainable procurement is integrated into the whole project life, from the identification of needs, through to the end of the useful life of the asset or service, and means that the development will be in compliance with all appropriate regulations, polices, and laws (Boswell and Walker 2004). In efforts to develop sustainable procurement practices, a range of strategies, policies, and regulations have been established to improve and enhance project delivery (Boswell and Walker 2004). Although a variety of initiatives to develop sustainable procurement exist, a significant problem remains regarding how they are taken from policy to sustained application (Dickinson et al. 2008). However, from the perspective of many developing countries, the formation and implementation of supporting policies is the initial challenge.

\section{Construction and Sustainability in Jordan}

Jordan faces a variety of challenges shared by other developing countries in the Middle East. One of the most pressing challenges is that of rapid urbanization. Approximately $80 \%$ of the general population reside in urban areas and $70 \%$ of its population lives within $30 \mathrm{~km}$ of the capital, Amman (Kisbi 2011). As a result, a large burden is placed on public buildings, infrastructure, services and the environment. Jordan also suffers from problems shared by the international community, e.g., increasing energy concerns and levels of pollution (Ali and $\mathrm{Al}$ Nsairat 2009). Jordan is already one of the World's most water-stressed countries, with 95\% of its land mass being desert and much of the rest susceptible to desertification (Kisbi 2011). Consequently, concerns about Jordan's ability to develop in a sustainable manner are increasing. In reacting to these growing concerns, Jordan initiated the National Environmental Strategy (NES) - the first of its kind in the region. Since 2009 the Jordanian Green Building Council has advocated for environmentally responsive construction concepts and practices, which has seen the implementation of a variety of building codes targeting sustainable construction. From this, the Energy Efficient Building Code was established to meet Jordan's energy challenges and recently, the Institute for Sustainable Development Practice (ISDP) was launched with the aim of tackling a variety of sustainable development issues.

Despite these improvements, a number of challenges remain that continue to beleaguer Jordan's construction industry and its move toward sustainable development. Large delays and cost overruns are reported (Al-Momani 1995, 2000; Sweis et al. 2008), significant legal problems are widespread (Al-Momani 1995), there are no clear indicators of productivity and growth available, and critical data on the sector remain largely unavailable (EnConsult 2007). Further, neither construction companies or construction projects are currently benchmarked internally or externally, and a significant knowledge gap exists in the industry pertaining to KPIs and benchmarking methods (Alkilani et al. 2012).

\section{Methodology and Findings}

The study reported in this paper is part of a wider PhD-based research program into the Jordanian construction industry, its aim being to develop a performance measurement framework and define KPIs and benchmarking processes. The study presented here utilises data collected from the second stage of a two-part data collection strategy. Stage 1 (not reported here) was based on primary and secondary sources - a combination of: (i) expert interviews and semi-structured questionnaires, and (ii) existing literature and archival

Alkilani, S.G. and Jupp, J.R. (2012) 'Paving the road for sustainable construction in developing countries: a study of the Jordanian construction industry', Australasian Journal of Construction Economics and Building, Conference Series, 12 (1) $84-93$ 
material. This data was then used to feed into Stage 2 of the data collection program - a one day stakeholders' workshop, hosted at the headquarters of the Jordanian Construction Contractors Association (JCCA) and supported by the Ministry of Public Works and Housing (MPWH). A series of structured activities and discussion sessions were undertaken and the data collected from the workshop was analysed using thematic and statistical analysis. Twenty-nine professionals took part in the workshop. A diverse mix of construction industry actors were represented, with three main categories identified within the group, consisting of: (1) 16 public sector representatives from the MPWH, Ministry of Environment, and other government entities (each participant had a minimum of 15 years professional experience in consultancy, planning, management, economics and statistics), (2) 11 private sector representatives (including clients, contactors, project managers, engineers and consultants), and (3) two representatives from academia.

\section{Stakeholder Workshop}

The one-day stakeholders' workshop was aimed at gathering qualitative input on a range of issues pertinent to construction performance improvement with one of the issues focusing on sustainable procurement (identified via Stage 1 of the research programme). In designing the workshop's activities, challenges to sustainable procurement were first grouped thematically into five categories by the researchers so that participants could identify and list the underlying issues within each category. The five categories included the lack of: (i) Regulatory factors, (ii) Economic factors, (iii) Social/ Cultural factors, (iv) Administrative/ Organisational factors, and (v) Technical/ Innovation factors. During the workshop all five areas were discussed before participants were asked to: (a) rank their importance, (b) identify their underlying causes, and (c) rank each underlying cause. Rankings were based on a 7Point Likert Scale, where 1 is the least important and 7 is the most. The Relative Importance Index (RII) method (Kometa et al. 1994) was used to calculate the relative significance of each category's rank, revealing those deemed most significant. The RII is computed as:

$\mathrm{RII}=\frac{\sum W}{A \times N}$

Where $W$ is the weight given to each factor by the respondents and ranges from 1 to $7 ; A$ is the highest weight $=7$; and $N$ - the total number of respondents.

\section{Five Challenges to Sustainable Construction Procurement}

Data analysis revealed that Regulatory factors - with an RII of (0.92) - were perceived by participants as the most critical challenge to the development and application of sustainable procurement methods. The least critical barrier was perceived as Social/ Cultural factors with an RII of (0.43). Analysed responses are shown in Figure 1. The remainder of this paper focuses on the most critical challenge identified, i.e., Regulatory Factors.

Alkilani, S.G. and Jupp, J.R. (2012) 'Paving the road for sustainable construction in developing countries: a study of the Jordanian construction industry', Australasian Journal of Construction Economics and Building, Conference Series, 12 (1) $84-93$ 


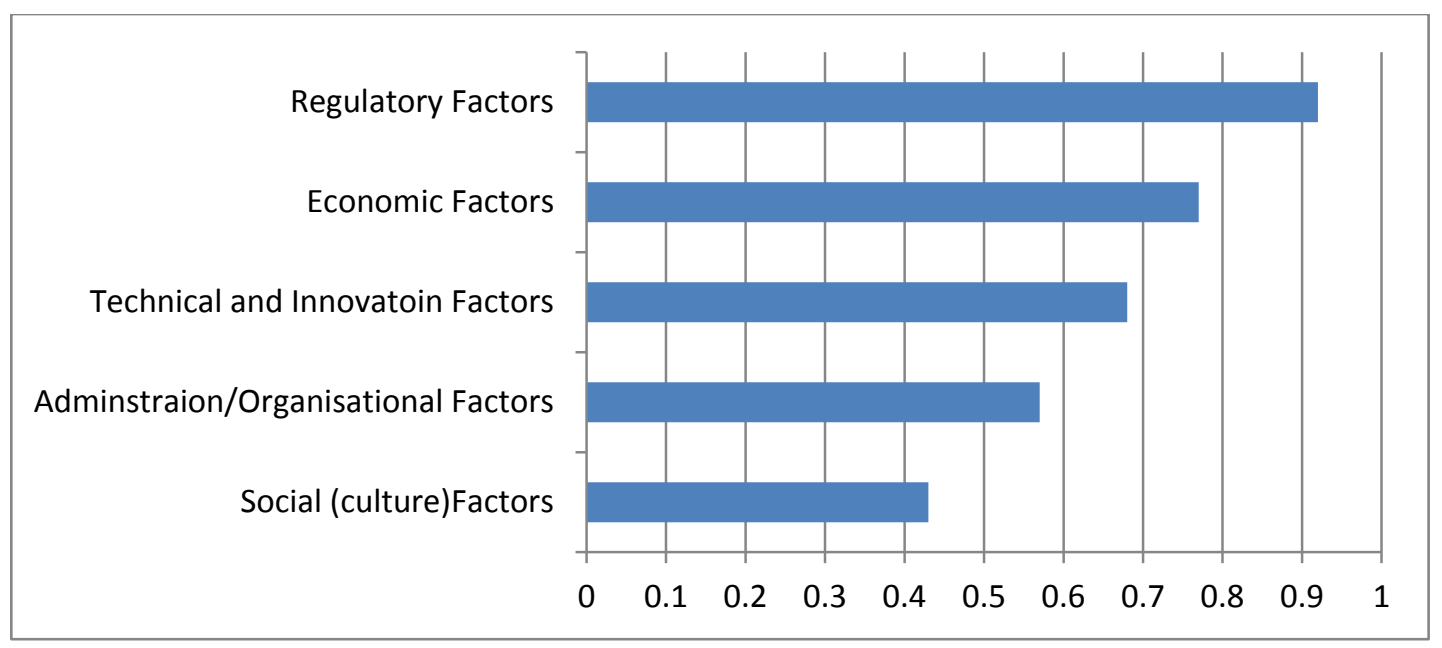

Figure 1: Underlying challenges for addressing sustainability in Jordanian construction procurement

\section{Regulatory Factors - Identification of Underlying Issues}

Participants reported that the "lack of" and "inadequacies in" the use, implementation and enforcement of a range of regulatory-based influences contributed to deficiencies in the application of more sustainable construction practices; they included current: (i) Public procurement methods; (ii) Policies and legislation, (iii) Financial inducements, (iv) Compliance and certification, and (v) Expertise and leadership. In facilitating workshop discussions, ranks and weights for each of the five issues identified above were allocated by participants, and using the RII method, as described in the preceding section, the following influences were revealed as having the 'most' and 'least' impact.

i- Public procurement methods - RII (0.92). As reported by respondents, the two stage method (design-build contracts) is most common in public sector procurement. In Jordan, it is mandated that construction contracts for public projects be undertaken by using competitive sealed bidding processes and awarded based on the lowest-price bid. Workshop participants agreed that this method prohibits the industry's ability to develop more sustainable construction practices, with one participant noting:

"My company is willing to move to sustainability practices, however, implementing sustainable solutions such as in designing, manufacturing or importing and selecting environmentally friendly materials, and other sustainable practices will cost me a lot of money, therefore in order to bid and win the contract I should present lowest price which means less sustainable practices".

Workshop Participant A (Construction Contractor)

Another participant adding:

“...the public sector represented by MPWH is very concerned with continuing the use of a traditional procurement route (calling for lowest-price tender), where this method does not take into account costs such as operating and maintenance which is part of the life cycle cost”. 
ii- Policies and Legislation - RII (0.86). Participants reported a lack of policies and legislation (from the MPHW) governing sustainability in construction (in particular for public and private housing development), which results in major deficiencies in the protection and monitoring of the impact of construction projects on the environment. Other examples raised by participants included the: (i) absence of instruments to undertake and regulate environmental impact assessment for large infrastructure projects, and (ii) lack of formal governance and monitoring of sustainable on-site construction practices. Whilst some government regulations and laws are in place to assist in implementing sustainability in construction (e.g. National Environmental Strategy, Green Building Assessment Tools, and Energy Efficient Building Codes), most remain optional.

iii-Compliance and Certification - RII (0.85). Another significant impact identified was the lack of compliance and certification standards suitable for Jordan's construction environment. This issue also related to the inadequate policies and legislation concerns identified above. Participants noted the lack of appropriate environmental assessment tools and measures, and absence of benchmarking processes that encompass apposite KPIs. Participants mentioned that whilst general initiatives exist they do not adequately or holistically address sustainable procurement issues.

iv-Financial inducement - RII (0.83). The cost of pursuing sustainable construction was cited as a major barrier to alternative sustainable construction technologies. High costs coupled with a lack of governmental funding to support the introduction of sustainable technologies were noted as being a significant challenge. Participants reported that the industry's lack of financial inducements and discouraging tax regulations prohibited innovation and adoption of sustainable building solutions. Participants also mentioned that current reductions in funding for public projects were beginning to hinder efforts by the private sector to innovate and adopt more sustainable construction methods. Other participants reported deficiencies in research investment and a lack of promotion of alternative clean technologies.

v- Expertise and leadership - RII (0.79). The final issue reported by workshop participants surrounded reported deficiencies in expertise and leadership within the public sector. This was seen to reflect the lack of public sector commitment to sustainable construction procurement objectives. Participants noted that critical decision-making responsibilities pertaining to sustainability issues were often allocated to public sector personnel who lacked the appropriate knowledge and expertise in sustainable construction issues.

\section{Discussion and Recommendations}

The research findings reported above show that sustainable construction practices are perceived as a necessary but optional practice in Jordan. Whilst government bodies in Jordan have begun to pay attention to aspects of sustainable construction, it is not due to internal convictions, but rather due to international standards. The five underlying issues pertaining to regulatory factors are somewhat interconnected and together act as a significant barrier to establishing sustainable construction procurement in Jordan. Current procurement routes favoured by public sector projects are based on encouraging the lowest-price bid which 'disincentivizes' contractors to invest in sustainable procurement practices. This issue is underpinned by the lack of a comprehensive regulatory framework for sustainability that supports compliance and certification methods, provides financial inducements and defines

Alkilani, S.G. and Jupp, J.R. (2012) 'Paving the road for sustainable construction in developing countries: a study of the Jordanian construction industry', Australasian Journal of Construction Economics and Building, Conference Series, 12 (1) $84-93$ 
leadership roles and responsibilities. Compounding these challenges is the absence of performance indicators and benchmarking processes on which industry practices can be measured and monitored. In seeking to advance sustainable procurement in Jordan these challenges must be tackled collectively.

An integrated strategy that incorporates a top-down and bottom-up approach to government-industry action is required. Figure 2 illustrates this combined approach to supporting sustainable construction procurement, showing how macro- and microdimensions of the construction industry are accounted for.

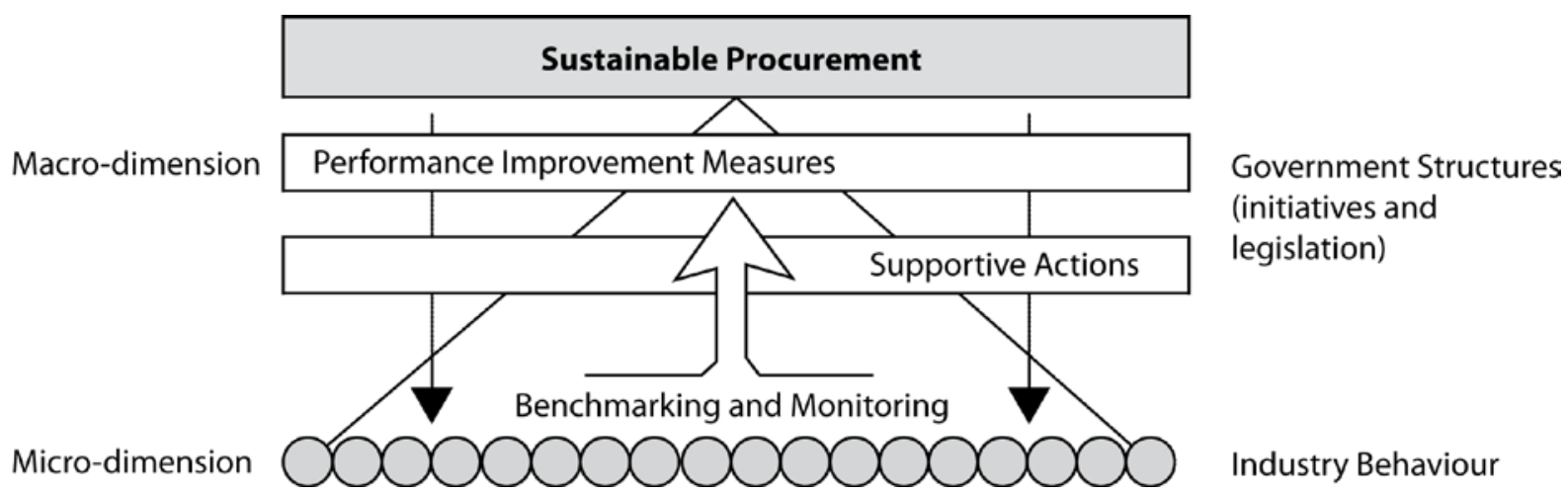

Figure 2: Supporting sustainable construction procurement (top-down and bottom-up)

From individual behaviours emerges the synthesis of collective industry behaviours (microdimension). To encourage best practice in industry behaviour this integrated approach requires two forms of support mechanisms (macro-dimension), established via Government structures, namely: (i) Performance improvement measures, and (ii) Supportive actions. Each mechanism can be integrated within current procurement methods but are primarily aimed at supporting business process change and new industry behaviours in sustainable procurement. The following section elaborates on the strategies contained within each mechanism.

\section{Performance Improvement Measures}

Indicators for sustainable development: KPIs focusing on sustainable construction practice that are sensitive to the context of Jordan should be established and agreed to by project stakeholders. KPIs concerning the measurement of potential social, environmental and economic impacts of construction are critical to the approach. For example, social KPIs include occupant comfort, access to facilities, employment generation, urbanisation, etc; while economic KPIs include capital cost, on-going cost, materials cost, etc.; and environmental KPIs target water and energy consumption, waste, materials and components, etc. Indicators related to the performance of construction processes and products should be established in conjunction with appropriate compliance and certification standards that support sustainable methods, practices and technologies. Indicators should be based on sustainable procurement processes that start at project inception (so as to consider selection of construction materials, land-use, water and energy consumption, waste and natural resources, etc.), and continue throughout design, tendering construction, handover and operation.

Alkilani, S.G. and Jupp, J.R. (2012) 'Paving the road for sustainable construction in developing countries: a study of the Jordanian construction industry', Australasian Journal of Construction Economics and Building, Conference Series, 12 (1) $84-93$ 
Standardising benchmarking programs: Standardisation of KPIs and benchmarking programs that enforce sustainable construction practices are required so as to require construction companies to not only monitor practices but to also effectively benchmark against each other and establish standards of best practice. This should include, e.g., monitoring of environmental impact of on-site activities, implementation of ISO 14001 to ensure consistency, and embedding of sustainability-based assessment criteria in construction processes. Improved transparency among contractor, manufacturer, and supplier classifications, certifications and product approval systems should also be part of standardisation processes. Institutional capacity could also be developed to encourage the use of environmental evaluation systems surrounding construction activities.

\section{Supportive Actions}

Policy and legislative reforms: Whilst a number of policies and initiatives aimed at promoting sustainable construction have been implemented in Jordan, and some examples of sustainable construction projects recorded, such practices are largely optional. To overcome the barriers identified the government needs to develop and mandate new policies whilst also enforcing existing legislation including the National Environmental Strategy (NES) for public land-use. The government should also enforce the higher standards surrounding the use of renewable energy and waste management, setting penalties for non-compliance.

Mapping needs to triple-bottom-line: The introduction of government endorsed frameworks that enable project requirements to be mapped onto the triple-bottom-line are required. From a lifecycle perspective, such frameworks must enable project teams to identify needs at the inception and planning stage, mapping all dimensions of the "triple-bottom-line" with project requirements and constraints. It will be necessary to define processes for how projects undertake evaluation processes during early project phases, e.g., via feasibility studies that involve wider stakeholder representatives so as to consider all social, economic and environmental requirements.

Provision of financial incentives: Financial incentives will require government support, including making grant funds available for establishing sustainable procurement methods and related best practices; starting from project feasibility studies, e.g., employing accredited professionals to advise stakeholders of sustainable procurement processes and construction practices, and concluding with the implementation of asset and facility management strategies in operation. Government tax reform may also be necessary in Jordan so as to provide tax incentives for contractors adopting sustainable procurement methods and innovating in sustainable best practices. Additional government support for non-government organisations (NGOs), such as Jordan's Green Building Organisation, is also recommended so as to provide funds for R\&D, education and training.

Alternative procurement processes: Alternatives to the current two-stage procurement methods should be adopted across public sector development projects as well as appropriate private sector projects. To enable Jordan to move towards more sustainable construction practices, the evaluation of contractors during tendering is key; this means contractors need to demonstrate their capacity and track record in sustainable construction methods, practices and technologies. Incorporating the KPIs discussed (to assess sustainable construction development), during tendering processes will enable contractors to be benchmarked against each other.

Alkilani, S.G. and Jupp, J.R. (2012) 'Paving the road for sustainable construction in developing countries: a study of the Jordanian construction industry', Australasian Journal of Construction Economics and Building, Conference Series, 12 (1) $84-93$ 


\section{Conclusion}

Like other developing countries in the Middle East, Jordan faces various interdependent challenges to achieving more sustainable procurement methods and practices, making its pursuit particularly difficult. The lack of sustainable performance measures, benchmarking processes, and ineffective procurement systems combined with poor regulatory frameworks that discourage best practice are among the major barriers to achieving sustainable procurement. For Jordan to embark on a path of sustainable construction procurement, a strategic alliance between government and industry, (including research institutes) is proposed as an effective approach to tackle the challenges identified. A key role however resides at the government level, where new policies and the enforcement of existing legislation are required. The findings of this study demonstrate that robust government interventions will require the implementation of KPIs and benchmarking processes that support the objectives of sustainable procurement. The authors recommend two types of mechanisms to establish sustainable procurement practices in Jordan - performance improvement measures and supportive actions - intended to promote collaborative government-industry action via top-down structural changes and monitoring of bottom-up industry behaviour change.

\section{References}

Adrien, P. and Laura, M. (2010). 'Benchmarking for sustainability: an application to the sustainable construction industry.' Benchmarking, 17(3), p. 435.

Al-Momani, A.H. (1995). 'Construction practice: the gap between intent and performance.' Building Research \& Information, 23 (2), 87 - 91.

Al-Momani, A.H. (2000). 'Construction delay: a quantitative analysis.' International Journal of Project Management, 18(1), 51-59.

Ali, H.H. and Al Nsairat, S.F. (2009). 'Developing a green building assessment tool for developing countries - Case of Jordan.' Building and Environment, 44(5), 1053-1064.

Alkilani, S., Jupp, J. and Sawhney, A. (2012). 'A case study of characteristics of the Jordanian construction industry: Readying a developing economy for implementing of perfromance measurement and benchamrking.' Visions for the future of housing: Mega cities, IIAHS World Congress on Housing, Turkey.

APCC (2012). Australian Procurement and Construction Council Inc, Australia, retrieved from: http://www.apcc.gov.au/Publications/Procurement/tabid/127/Default.aspx.

Boswell, P. and Walker, L. (2004). Procurement and Process Design, FIDIC and Lorna Walker Consulting Ltd., Geneva/London.

Dickinson, McDermott and Platten (2008). 'Implementation of sustainable procurement policy innovations.' Proc, Construction in Developing Countries: Procurement, Ethics and Technology, 16 - 18 January 2008, Trindad and Tobago.

Ding, G.K.C. (2008). 'Sustainable construction-the role of environmental assessment tools', Journal of Environmental Management, 86(3), 451-464.

Egan, S.J. (1998). Rethinking Construction: the report of the construction task force to the deputy prime minister, on the scope for improving the quality and efficiency of UK construction, Department of the Environment, Transport and the Region, London.

Alkilani, S.G. and Jupp, J.R. (2012) 'Paving the road for sustainable construction in developing countries: a study of the Jordanian construction industry', Australasian Journal of Construction Economics and Building, Conference Series, 12 (1) $84-93$ 
EnConsult (2007). Construction and related engineering sevices sector and architectureal and related engineering services sub sector, Envision Consulting Group, Amman.

Geng, Y. and Doberstein, B. (2008). 'Greening government procurement in developing countries: Building capacity in China.' Journal of Environmental Management, 88(4), 932938.

Hassan, O.A.B. (2006). 'An integrated management approach to designing sutainable buildings.', Journal of Environmental Assessment Policy \& Management, 8(2), 223-251.

Khalfan, M.M.A. (2006). 'Managing sustainability within construction projects.' Journal of Environmental Assessment Policy \& Management, 8(1), 41-60.

Kisbi, Y. (2011). 'Construction in Jordan melds old and new methods for energy efficincy', Washington Times.

Kometa, S.T., Olomolaiye, P.O. and Harris, F.C. (1994). 'Attributes of UK construction clients influencing project consultants' performance.' Construction Management \& Economics, 12(5), 433-443.

Latham, M. (1994). Constructing the team. final report of the government / industry review of procurement and contractual arrangements in the UK construction industry. Design, Drawing and Print Services, Department of the Environment, HMSO, London.

Ofori, G. (1992). 'The environment: the fourth construction project objective?' Construction Management and Economics, 10(5), 369-395.

Ofori, G. (2001). 'Indicators for measuring construction industry development in developing countries.' Building Research \& Information, 29(1), 40 - 50.

Shah, H.H., Ma, Y. and Gulliver, S.R. (2010). 'Selecting key performance indicators for sustainable intelligent buildings', Proc., First Interdisciplinary Workshop on Communication for Sustainable Communities, 26 - 29 September 2010, Sao Paulo, Brazil.

Spence, R. and Mulligan, H. (1995). 'Sustainable development and the construction industry.' Habitat International, 19(3), 279-292.

Sweis, G., Sweis, R., Abu Hammad, A. and Shboul, A. (2008). 'Delays in construction projects: the case of Jordan', International Journal of Project Management, 26(6), 665674.

Thomson, J. and Jackson, T. (2007). 'Sustainable procurement in practice: lessons from local government.' Journal of Environmental Planning and Management, 50(3), 421-444.

UNDP (2008). Environmental Procurement, Practice Guide, UNDP Procurement Support Office

Wilkinson, S. (2007). 'The structural and behaviourial barriers to sustainable real estate development. ' Proc., American Real Estate Society (ARES) Conference, 11-14 April 2007, San Francisco, USA.

Alkilani, S.G. and Jupp, J.R. (2012) 'Paving the road for sustainable construction in developing countries: a study of the Jordanian construction industry', Australasian Journal of Construction Economics and Building, Conference Series, 12 (1) $84-93$ 